\title{
Intergroup Contact and Negative Attitudes Towards Immigrants Among Youth in Sweden: Individual and Contextual Factors
}

\author{
Beint Magnus Aamodt Bentsen ${ }^{1}$
}

Accepted: 6 April 2021/Published online: 14 May 2021

(C) The Author(s) 2021

\begin{abstract}
Negative attitudes towards out-groups have been of academic interest for many years - and even more so with the increased levels of migration to European countries in recent years. Building on insights from intergroup contact theory, this paper seeks to extend our knowledge of the association between contact and negative attitudes toward immigrants among youth in Sweden. Multiple regression analysis and fixed effects models are used to analyze a large, high-quality dataset on Swedish adolescents based on representative survey information, complemented with extensive registry data and official statistics. Our objective is to measure contact on different levels in order to better understand the importance of these different contact variables' associations with negative attitudes. The results of the analysis indicate that high-quality contact in the form of friendship is associated with a reduction in negative attitudes among Swedish adolescents, even after controlling for background variables. Superficial forms of contact - measured on the school level — are, on the other hand, associated with an increase in negative attitudes.
\end{abstract}

Keywords Contact theory $\cdot$ Attitudes $\cdot$ Youth $\cdot$ Sweden $\cdot$ Fixed effects

\section{Introduction}

In this article, we examine the relationship between intergroup contact and attitudes towards immigrants among adolescents in Sweden. Our particular focus is on the relative importance of intergroup friendship and the presence of immigrants in the local municipality and the respondents' school classes. Contact has been given much attention by researchers in recent years due to its potential as a way of reducing

Beint Magnus Aamodt Bentsen

Beint.Magnus.Aamodt.Bentsen@mau.se

1 Malmö Institute for Studies of Migration, Diversity and Welfare (MiM), Malmö University,

Malmo, Sweden 
negative attitudes at a time when migration has become increasingly common. The proportion of the population who is foreign-born is at a record high in many countries, including Sweden. As there are more immigrants, then negative attitudes and connected outcomes such as discrimination - or even hate crime - could affect ever larger numbers of people and communities (Coenders and Scheepers, 2008; McLaren, 2003). This further increases the importance of understanding how negative attitudes can be mitigated and what the specific conditions are that affect negative attitudes.

Contact with out-group, such as immigrants or, generally, ethnic minorities has been found to be particularly effective at reducing negative attitudes. The basic premise that contact has a positive effect on attitudes is supported by previous research (Pettigrew and Tropp, 2011), including longitudinal studies (Binder et al., 2009; Schmid et al., 2014; Van Laar et al., 2005). For example, the presence of immigrants in all of Norway's municipalities has been shown to be a significant explanatory factor for reduced negative attitudes toward immigrants (Hellevik and Hellevik, 2017). In recent decades, research on intergroup contact has developed significantly to now address indepth the degree to which intergroup contact affects the level of negative attitudes towards immigrants and the conditions that mediate the effect of such contact. One recurring finding is that friendship as a type of contact is of special importance in relation to the level of negative attitudes (Davies et al., 2011). This effect was predicted by Allport (1954) in his initial formulation of the contact hypothesis. However, recent research has found that even more-superficial forms of contact may also contribute to the reduction of negative attitudes (Pettigrew and Tropp, 2011). The need for further research has been identified - notably by Hodson (2011) and Pettigrew and Tropp (2011) - if we are to understand the factors contributing to lower levels of negative intergroup attitudes. Hodson (2011) calls for more studies on the effect of contact in populations with relatively low levels of negative attitude - a criterion which Sweden fulfills. Pettigrew and Tropp (2011) point to the need for more studies that take into account the multilevel nature of contact.

Whereas previous research similar to this does exist, the focus has been on adult groups (Hamberger and Hewstone, 1997; Wagner et al., 2006). Isolating the association between attitudes towards immigrants and different types of contact in specific, distinguishable settings has, to our knowledge, not been addressed empirically for adolescents.

The case of Sweden is of special interest because the country has traditionally been tolerant and accepting of difference - as evidenced by the low levels of negative attitudes toward immigrants - and has, furthermore, experienced a greater change towards positive attitudes than most other European countries over the past decade and a half (Czaika and Di Lillo, 2018). This change is particularly interesting as Sweden, during this same period, had a substantial increase in the number of foreign-born residents with an immigrant background - by the end of 2019, immigrants and their children made up about $20 \%$ of the population. In contrast, several countries with few immigrants show high (Gorodzeisky and Semyonov, 2020) and, in some cases, increasing levels of negative attitudes over a comparable timeframe (Czaika and Di Lillo, 2018). This runs contrary to the common assumptions about the connection between immigrant population levels and attitudes towards immigrants which are often present in public conversation - contrary to the substantial amounts of research within group-threat approaches to attitude studies. In this theoretical framework, negative 
attitudes are thought to increase when the majority feels that their economic or cultural position is challenged by large numbers of minorities (Blalock, 1967; Blumer, 1958; Dixon, 2006; Hjerm and Nagayoshi, 2011). We believe this further contributes to making Sweden an interesting case.

Immigration to Sweden began in significant numbers after World War 2; up until the 1980s, it was mainly labor migrants who went to Sweden from Europe and Sweden's Nordic neighbors. Since the 1980s, immigration to Sweden has largely been dominated, firstly, by refugee migration from outside Europe and, secondly, by intra-EU migration. In addition, there have been significant arrivals of family-reunification migrants, due to the country's very liberal policies (Borevi, 2018). Although the aforementioned measurements of negative attitudes in Sweden show that people in general have a high acceptance of immigration and immigrants, Demker and Van Der Meiden (2016) show that those who do have highly negative attitudes view immigrants as a cause of serious social problems and as a threat. However, such people are relatively few in number and this is thought to be a possible explanation for Sweden being very late - in a European context - in having a successful anti-immigrant political party. The Sweden Democrats first entered parliament in 2010 and have since mobilized around a discourse focusing on immigration and national identity (Hellström and Edenborg, 2016) - in the 2014 election they gained just under $13 \%$ of the vote.

To have a focus on adolescents is important for several reasons. Conditions that affect the attitudes of adolescents have been found to have a formative effect that also lingers later in life, as demonstrated by Coenders and Scheepers (2008). Longitudinal studies have shown that, among adolescents, contact with minorities both promotes the development of more positive attitudes and reduces the transmission of negative attitudes from the young peoples' parents and peers (Jugert et al., 2016; Miklikowska, 2017). Miller and Sears (1986) have also demonstrated that there is a significant persistence in attitudes throughout the life course. Extant research, in sum, underscores the importance of studying attitudes and intergroup contact among adolescents. As the next generation of voters and the next workers to enter the labor market, adolescents are an important topic of study because of what such research can tell us about future developments in these spheres. Furthermore, this age group is overrepresented among perpetrators of xenophobic crimes (Bjørgo, 1997; Wahl, 2002). Therefore, identifying factors that can contribute to reducing negative attitudes towards out-groups in this age bracket and the circumstances under which these factors operate is of significant value for social theory, research and policy. Finally, outside of the school setting, adolescents are understudied in research on intergroup attitudes. To our knowledge, none exists that isolates the association between the different forms of intergroup contact and friendship and the attitudes of adolescents towards immigrants.

The main aim of this article is therefore to improve our understanding of which factors are associated with adolescents' negative attitudes towards immigrants and to enable us to determine the relative importance of contextual and individual factors. In pursuit of this general goal, the following specific questions guide this study. First, does intergroup contact correlate with Swedish adolescents' attitudes towards immigrants, after controlling for other well-known factors? Second, is the size or direction of the correlation between contact and negative attitudes dependent on the type and amount of contact? The third question we wish to address is whether superficial forms of contact in the school and the local municipality contribute to understanding such negative 
attitudes beyond what is explained by friendship and the high-quality contact that it represents. Finally, we ask what the relative importance of individual-level contact is as opposed to contact gauged by aggregate measures in the school class and local municipality?

This study contributes to attitudes research due to the use of multiple measures of contact on different levels and its focus on adolescents in Sweden, a country with a relatively large immigrant population yet with a relatively low level of negative attitudes toward immigrants. The study is based on a large and representative survey of more than 7000 adolescents. The resulting data are of high quality due to the inclusion of individual, demographic, and school information derived from registry data, which is further supplemented by other official statistical sources. The result is a unique dataset with extensive high-quality data on both individual and structural levels that allow for a detailed investigation of intergroup attitudes among adolescents in Sweden.

\section{Theoretical Framework and Past Research}

\section{Contact Theory}

Gordon Allport (1954, p. 281) made the first comprehensive formulation of contact theory in his book The nature of prejudice, hypothesizing that:

Prejudice (unless deeply rooted in the character structure of the individual) may be reduced by equal status contact between majority and minority groups in the pursuit of common goals. The effect is greatly enhanced if this contact is sanctioned by institutional supports (i.e., by the law, costume, or local atmosphere), and provided it is of a sort that leads to the perception of common interest and common humanity between members of the two groups.

According to contact theory, social contact between majority and minority members can contribute to reducing negative attitudes between groups. This basic effect of outgroup contact on attitudes has been empirically established through significant research over the past half century (eg. Brown and Hewstone, 2005; Pettigrew and Tropp, 2011; Pettigrew et al., 2008). However, the theory also states that contact needs to reach below the surface if it is to have the predicted effect and that superficial contact and contact under conditions of competition or conflict cannot be expected to be effective. Allport's (1954) claim was that contact needs to be between individuals of equal status, in pursuit of common goals or otherwise amicable. Furthermore, he thought that the effect of contact could be enhanced if there was institutional support and if the contact led to a perception of common interest and humanity.

Much progress has been made in refining and establishing empirical support for these initial predictions of contact theory. Pettigrew and Tropp's (2011) meta-analysis of all research on contact (published before 2001) offers perhaps the best summary of these developments. In their analysis, they show that, in the literature to date, establishing Allport's optimal conditions in a contact situation does increase the effect of 
contact but is not necessary. Superficial contact in general also reduces negative attitudes, although to a lesser degree. The effects of contact are also shown to be significant across different settings, target groups, age groups, and geographical areas. Through this primary transfer effect, from individuals to groups, contact reduces negative attitudes toward out-groups (Gieling et al., 2014; Pettigrew and Tropp, 2011). This effect reveals the potential importance of intergroup contact in reducing negative attitudes and hence of the interest that contact merits as a moderator of negative attitudes. Recently, Laurence and Bentley (2018) further nuanced what previous research has taught us by showing that increased ethnic diversity may lead to both more-positive and more-negative contact: they reveal that, while the net effect of contact is more-positive attitudes, there is also increased polarization, as some people have predominantly negative interactions and thus increasing levels of negative attitude. Stark et al. (2015) show similar results for contact in schools.

In Sweden, research on the significance of contact for attitudes towards immigrants corroborates the findings in the literature but the overall picture is somewhat unclear. Liebkind et al. (2004) find that more contact predicted less-negative attitudes, with an individual-level measure of contact ranging across many types of personal contact. In a large survey of Swedish adolescents, Lövander (2010) shows that having immigrant friends is associated with lower levels of negative attitudes. This result is corroborated by Miklikowska (2017) in a smaller but longitudinal study. Hjerm et al. (2018) find that having a homogeneous social network leads to more negative attitudes over time, while Hjerm (2009) and Hjerm and Nagayoshi (2011) use the proportions of the immigrant population in a municipality and in smaller local areas respectively to study the effect of the immigrant presence on attitudes in a group-threat framework. The results indicate an increased level of negative attitudes when the Muslim immigrant population is large and, if there has been a recent influx of immigrants, for people in genuine competition with immigrants in the labor market. However, a negative correlation between the presence of the most visible immigrant groups and anti-immigrant attitudes leads, through the use of this approach, to an overall somewhat unclear picture. There is no research on attitudes towards immigrants that uses both individual and aggregate measures of contact in Sweden although, on the individual level, results are clearly in line with contact theory's predictions.

There are many identified mediators of the effect of intergroup contact on attitudes to groups. According to Pettigrew and Tropp (2008), the most important are, in descending order, a reduction in anxiety, an increased ability to empathize with and take the perspective of out-group members, and an increased knowledge about the outgroup. They also suggest that there may be a process whereby the initial contact causes a reduction in anxiety which, in turn, facilitates an increased knowledge and development of empathy in future encounters.

Contact has also been shown to reduce negative attitudes for persons who are highly intolerant. It has been indicated that this may even be where the effect is strongest (Hodson, 2011). Because of this we believe that, in a context such as Sweden, where negative attitudes are generally already low, the effect of contact may be expected to be more moderate, given that the potential for improvement is smaller. Based on the ways in which contact is thought to reduce negative attitudes, there is a possibility that the initial and effective reduction in negativity has already occurred and that any further reduction will need more-extended and repeat contact for the reduction to happen than 
in populations with high levels of negative attitudes. This type of threshold in attitude change has been observed in the past (Hodson, 2011; Pettigrew, 1997) and might be expected to be present in the current case as well. Thus, there is reason to suspect that superficial contact may have a smaller association with negative attitudes here than in previous studies.

In contact research, the degree of association between contact and attitudes has been seen to vary significantly when contact is analyzed through different operationalizations and measured at several levels of analysis. Direct contact on the individual level is, as already illustrated, predominantly found to be associated with more-positive attitudes (Pettigrew and Tropp, 2011). Friendship with out-group members has, in the past, consistently been correlated with more positive attitudes and is found to be an especially powerful type of intergroup contact (Davies et al., 2011). Several studies have corroborated that friendship with out-group members averages significantly higher associations with attitudes than more-superficial forms of contact (Dixon, 2006; Hamberger and Hewstone, 1997; Pettigrew, 1997).

At higher levels of analysis, the proportion of minority-group members in a small area, such as a neighborhood, municipality or region, has often been used as a proxy for contact, with the rationale that a high proportion of minority-group members will lead to more contact (Vermeij et al., 2009; Wagner et al., 2006; Weber, 2015). This approach has also received a fair degree of criticism in recent years. For example, Pettigrew and Tropp (2011) warn that proximity does not necessarily lead to contact; therefore, it is important not to overstate the significance of any such variable, which can measure proximity but does not guarantee contact, particularly in settings where spatial or social segregation is significant. However, Wagner et al. (2006) found, in a survey of German adults, that the percentage of immigrants in an area predicted contact opportunities in the workplace and the local community and that these translated into more contact and less-negative attitudes.

When, in past research, variations in attitudes have been connected to out-group contact in school, this has yielded varying results. Some studies found that ethnic diversity in the school class has no effect on attitudes (Bekhuis et al., 2013), while others found positive effects (Agirdag et al., 2011; Juvonen et al., 2006). Yet other research finds that ethnic diversity leads to higher levels of negative attitudes (Vermeij et al., 2009; Vervoort et al., 2011). Thijs and Verkuyten (2014) suggest, in a review of the literature, that the lack of clear results within this avenue of research may reflect differences in the operationalization of attitudes and varying measures of contact. Nevertheless, some of the variation found in the results must also be accounted for by ethnic composition and the actual level of intergroup contact existing in classes. They conclude that greater ethnic diversity is directly related to more-positive attitudes among youth in schools, particularly when Allport's (1954) optimal conditions for contact are established, otherwise the effect is not very strong. One aim with using multiple measures of contact on all these three levels of analysis is to specifically address this variation in the observed correlation of contact and attitudes. When we control for contact on all three levels, a degree of uncertainty - that many past studies have not been able to eliminate - is removed.

To summarize, both theory and recent research highlight specific objectives for the present project. There is a need to examine the nature of contact - for example, highly meaningful contact versus more-superficial contact — in relationship to attitudes 
toward migrants (Pettigrew and Tropp, 2011). Previous research on attitudes among youth has not focused on isolating the effects of contact on different levels. Considering how common it is to use some form of aggregate-level measure as a proxy for contact, we believe that the current approach of this paper has the potential to make an important contribution to the research literature by allowing conclusions to be drawn about the explanatory power which these have after controlling for individual-level contact.

\section{Research Questions}

To guide our analysis, we have formulated four research questions. Firstly, we ask whether intergroup contact correlates with Swedish adolescents' attitudes towards immigrants, after controlling for other well-known factors. We wish to test whether the most foundational prediction of contact theory also holds true in this sample of Swedish adolescents. There is reason to expect a more moderate association between contact and negative attitudes than previous studies have found, due to the fact that the level of negative attitudes in Sweden is relatively low compared to other countries (Czaika and Di Lillo, 2018). Hodson (2011) found that contact may be the most effective for individuals with highly negative attitudes; the ways in which contact is believed to reduce negative attitudes, according to Pettigrew and Tropp (2008), indicate that initial contact may have the strongest effect. Secondly, we ask whether the size or direction of the correlation between contact and negative attitudes are dependent on the type and amount of contact, in order to determine the relative importance of the three different contact variables. For the friendship variable, in particular, we wonder whether more friends give a stronger association or whether any amount of highquality contact is sufficient to obtain a significant association. The third question we wish to address is whether superficial forms of contact in the school and local municipality contribute to the reasons behind negative attitudes beyond what is explained by friendship and the high-quality contact that it represents. Due to the previous findings whereby increased contact led to both more positive and more negative contact, we wonder whether the superficial contact variables have any explanatory value after high-quality contact is accounted for. Finally, we ask what the relative importance is of individual-level contact as opposed to contact determined by aggregate measures in the school class and local municipality - which should enable us to find out what relative importance all the variables on the three levels have.

\section{Data and Method}

The dataset we employ was composed for The Living History Forum (Forum För Levande Historia) by Statistics Sweden (Statistiska centralbyrån, SCB) through a survey taken among adolescents in 473 classes in schools throughout Sweden in 2014. The population for the study consisted of adolescents in Sweden in the last year of primary school (Arskurs 9) and years 1-3 of secondary school (Gymnasiets Arskurs $1-3)$. The normal age range for these school years is 14 to 19 , but due to the possibility of starting school one year early, and finish secondary school later the sample also contains 16 respondents that are 13 or 20-21 years old. The final sample consisted of 
6664 respondents. ${ }^{1}$ For the purpose of the analysis, respondents who had themselves immigrated, and respondents with two immigrant parents are not included, thus further reducing the sample to 5220 .

In addition to the information gained from the survey, the dataset also includes individual information from the School Registry (Skolregisteret), Pupil Registry (Elevregisteret), and Population Registry (Register över totalbefolkningen, RTB), all with the respondents' permission (see Statistics Sweden, 2014). In addition to these sources, we include municipality-wide data from Statistics Sweden's demographic database and from the Swedish Labor Office (Arbetsförmedlingen). A detailed table of descriptive statistics can be found in Appendix.

\section{Use of the Term "Immigrant"}

A pilot study was conducted prior to data collection where respondents' interpretations of questions and terms used in the survey were analyzed. Terms like "immigrants," in particular, may be interpreted to mean different things. As pointed out by Bevelander and Otterbeck (2016), "immigrant" is often used in a broader way than simply "a person who has immigrated to Sweden." Everyday use of the term "immigrant" often includes people of immigrant descent more generally and reflects popular ideas concerning appearance, religion, culture or other identifying traits. Our pilot study found that "immigrant" is a salient social category for our responding adolescents and that this broad interpretation of the word corresponded with their understanding of it. The proportions of immigrants in our respondents' municipalities and school classes are calculated based on the number of individuals who have themselves immigrated or who have two immigrant parents according to the national registry (RTB). Immigrants in Sweden are a highly diverse group and hail from all parts of the world. At the time of data collection, about $16.5 \%$ of the population in Sweden were born in a different country. Of these, $32.5 \%$ had an Asian background, 20\% were from EU28 countries excluding the Nordic countries, $15.5 \%$ came from the other Nordic countries, $14.5 \%$ from non-EU European countries, 10\% from Africa, 4\% from South America, 2\% from North America, and the remaining $1.5 \%$ from other regions or of unknown origin.

\section{Selection and Operationalization of Variables}

The dependent variable in this study is the level of negativity in attitudes toward immigrants, hereafter "negative attitudes towards immigrants." This variable is measured as an index ranging from a low of 0 up to the highest level of negative attitude, indicated by 1 . The index is composed of four statements, with a Cronbach's alpha of .839. Respondents were asked to state how much they agree or disagree with these statements on a five-point scale:

Most immigrants are probably nice people.

It would be okay to live next door to an immigrant.

\footnotetext{
${ }^{1}$ The actual response rate was $71.7 \%$ and 7391 respondents. Due to the internal attrition of no item response, we include 6664 individuals.
} 
Immigrants cannot be trusted.

There are too many immigrants in Sweden. ${ }^{2}$

These assertions tap into a number of dimensions of attitudes toward immigrants including the acceptance of proximity, prejudices and preconceptions about immigrants - and both the cognitive and affective dimensions of attitudes, in line with other scales for measuring them (eg. Henry and Sears, 2002). Very importantly, these statements were also used in two previous questionnaires and the results are revealed in three reports on attitudes among Swedish adolescents (Lövander, 2010; Ring and Morgentau, 2003; Severin, 2014). The responses can be seen in Table 1.

\section{The Explanatory Variables}

Three different variables measure contact in this study. The first measure of contact is whether or not the respondent has friends who are immigrants and, if so, how many. Two more variables that measure contact were also created. The first of these uses the proportion of immigrants in the respondent's school class as a proxy for contact and the second the proportion of immigrants in the respondents' local area - measured as the municipality in which the respondent's school is located. A common measure of contact with immigrants is their relative number within a given geographical area, often the municipality, town, or city (Wagner et al., 2006). While proximity is a proxy for contact - making contact more likely — a common critique has been that the measure does not necessarily detect actual contact nor capture its nature.

Because of this, we use three different variables for contact, so that we will have a more reliable measure than any of the three variables would offer alone. The three variables cover contact that occurs in different settings and contact that is qualitatively different. While the special importance of friendship as a type of contact has been established in previous research (Davies et al., 2011), there continues to be calls for additional research that accounts for the social context (Christ and Wagner, 2013; Pettigrew and Tropp, 2011), as well as contact on multiple levels of analysis. This may allow for more-detailed conclusions about the significance of contact at different levels of analysis.

In this paper, we also distinguish between low- and high-quality contacts. Lowquality contact is likely to be superficial, short-term, adversarial, or involuntary. In short, this type of contact does not fulfill the conditions predicted by Allport (1954) to be necessary in order for contact to reduce negative attitudes. High-quality contact, on the other hand, fulfills all or almost all of Allport's optimal conditions and is amicable, voluntary, and happening under conditions of cooperation or common interest. Friendship is by definition high-quality contact but previous research has also pointed to contact which has friendship potential, as defined by Pettigrew (1997). Gaining friends is a process that takes time, and this research is cross-sectional in nature, so we think it important to acknowledge that amicable contact with friendship potential could occur that would not be captured by measuring friendship. A longitudinal research design

\footnotetext{
${ }^{2}$ The statements in the original language, Swedish, are: Invandrare är säkert hyggligt folk. Det skulle vara helt okej att bo granne med en invandrare. Invandrare går det inte att lita på. Det är alldeles för många invandrare i Sverige.
} 
Table 1 Responses to xenophobia index questions - total number and percentage

\begin{tabular}{|c|c|c|c|c|c|c|c|c|c|c|c|c|}
\hline \multirow[t]{2}{*}{$\begin{array}{l}\text { Do you agree with the } \\
\text { following statements? }\end{array}$} & \multicolumn{2}{|c|}{$\begin{array}{l}\text { No, not at } \\
\text { all }\end{array}$} & \multicolumn{2}{|c|}{$\begin{array}{l}\text { Mostly } \\
\text { untrue }\end{array}$} & \multicolumn{2}{|c|}{ Unsure } & \multicolumn{2}{|c|}{$\begin{array}{l}\text { Mostly } \\
\text { true }\end{array}$} & \multicolumn{2}{|c|}{$\begin{array}{l}\text { Yes, } \\
\text { absolutely }\end{array}$} & \multicolumn{2}{|l|}{ Total } \\
\hline & No. & $\%$ & No. & $\%$ & No. & $\%$ & No. & $\%$ & No. & $\%$ & No. & $\%$ \\
\hline $\begin{array}{l}\text { Most immigrants are } \\
\text { probably nice people }\end{array}$ & 157 & 3.1 & 227 & 5.3 & 842 & 16.1 & 2084 & 39.9 & 1860 & 35.6 & 5220 & 100 \\
\hline $\begin{array}{l}\text { It would be OK to live next } \\
\text { door to an immigrant }\end{array}$ & 157 & 3.0 & 189 & 3.6 & 593 & 11.4 & 1524 & 29.2 & 2757 & 52.8 & 5220 & 100 \\
\hline Immigrants cannot be trusted & 2409 & 46.2 & 1355 & 26.0 & 1,055 & 20.2 & 263 & 5.0 & 138 & 2.6 & 5220 & 100 \\
\hline $\begin{array}{l}\text { There are too many } \\
\text { immigrants in Sweden }\end{array}$ & 1347 & 25.8 & 888 & 17.0 & 1,432 & 27.4 & 890 & 17.1 & 663 & 12.7 & 5220 & 100 \\
\hline
\end{tabular}

might be able to capture this gradual development. However, as is also pointed out by Pettigrew (1997), the reduction of negative attitudes from contact is also a gradual process, so we believe that using the friendship variable to measure high-quality contact is well warranted. Individuals' positive contact beyond friendship should be captured by the two other variables.

\section{Friendship}

As outlined in the theory section, a measure of friendship with immigrants is a particularly critical variable for the robust measurement of the cross-group contact, particularly given the importance of social life among adolescents and the effects of these social processes for attitudes towards immigrants. In this study the concept of friendship is operationalized through respondents answering a question about how many friends they have who are immigrants, selecting from five alternatives: no immigrant friends; one immigrant friend; a couple of immigrant friends; many immigrant friends; or "I do not know." This variable has been recoded into a series of four dummy variables with "no immigrant friends" as the reference category.

\section{Contact in School}

Contact in school offers a measure of long-term proximity to out-groups. However, contact in this situation is not necessarily of high quality, as the school setting can be competitive and it can potentially be where social conflict is played out. There may be only superficial contact or, according to past research, sometimes predominantly negative relationships between majority and minority pupils that, through generalization, lead to more-negative attitudes toward the entire minority group (Gieling et al., 2014; Stark et al., 2015). In previous research, schools were the setting where diversity had the most often been found to lead to more-negative attitudes (Thijs and Verkuyten, 2014). Regardless, measuring contact in school has the advantage that pupils have limited capacity to choose with whom they share a class and, hence, the problem of self-selection bias is reduced. In this study, the variable for contact in school is measured through the inclusion of the proportion of immigrants in the respondent's class. 


\section{Contact in Local Area}

The variable for contact in the local area is expressed as the proportion of immigrants in each municipality and is thought to increase the likelihood of all types of interaction with immigrants (Wagner et al., 2009). Over and above the other two contact variables, this adds to the analysis the everyday interactions and casual contact opportunities which may occur with other members of the local community.

The use of proportions of immigrants as a proxy for contact is a source of uncertainty that requires some attention. As has been pointed out in earlier work, for example by Pettigrew and Tropp (2011), the proximity to a minority that the proxy indicates does not necessarily mean that there is any actual contact. This may pose a particular problem when the geographical area studied is large. In such cases, there is room for significant internal differences and the possibility that processes of spatial and social segregation will prevent contact and meaningful interaction between and among groups. However, in this study, the purpose of this variable is to capture contact that is not friendship and that does not occur in school. This is likely to be superficial contact, so it is not our interpretation that this variable would capture anything beyond proximity to or superficial contact with immigrants.

To minimize the risk that proximity may not indicate contact, we include municipalities, as they are the smallest geographical units for which data exist. It is, however, hard to completely satisfy any potential uncertainty. The correlation measure between the number of immigrant friends and the proportions of immigrants in the local area and school class show, respectively, $\mathrm{rs}=.257$ and $\mathrm{rs}=.287$. These relationships suggest that non-immigrant adolescents in areas with more immigrants also form more friendships with immigrants - in other words, that opportunities for contact actually can be associated with more actual contact. We do not believe that the type of proxy variable is problematic when it is used as a complement to other contact variables and when one does not overstate its potential to represent actual contact.

\section{Control Variables}

The control variables included are factors identified in previous research on the contact-attitude nexus. The full list of control variables is as follows: gender, living in a big city, parents' education level and occupational status, level of education/school track, immigrant background, and unemployment level in the municipality.

Gender and level of education are included because of their significant influence. Previous results for the effect of gender on attitudes are somewhat mixed, in general. Girls have usually been found to hold less-negative attitudes toward immigrants (Dixon, 2006; Hello et al., 2004; Ponce, 2017). A higher level of education is fairly consistently correlated with more-positive attitudes towards out-groups, although the strength of the correlation varies between the countries studied (Coenders and Scheepers, 2003). This has been found to be the case across Europe and North America (Hjerm, 2001) where evidence indicates that it is the education in itself that is the predominant cause, not competing explanations like socially desirable responding (Hainmueller and Hiscox, 2007; Vogt, 1997; Wagner and Zick, 1995). Whether the respondent lives in a large city or in a more-sparsely populated area is also controlled for with a dichotomous variable. The central municipalities of Sweden's largest cities 
— Stockholm, Gothenburg, and Malmö — are differentiated from the rest of Sweden. In so doing, we account for differences in attitudes between residents of central urban areas and those in more-sparsely populated places and smaller towns and cities. This is a distinction that has been observed in previous research by Bevelander and Hjerm (2015) and Gorodzeisky and Semyonov (2009). Age often has a significant association with negative attitudes, though the variation in age in the surveyed population is so small that we do not include it in the statistical analysis. Moreover, age correlates problematically with the school track variable. It was however tested in a non-reported model and found to have no significant influence. Education level is measured through school track. A significant difference in attitudes towards various out-groups has been observed between pupils in vocational school tracks and pupils on university y preparatory tracks (Gniewosz and Noack, 2008; Lövander, 2010; Severin, 2014). Immigrant background is controlled for through the respondents' parents' immigrant origins. This variable distinguishes between respondents with two parents from Sweden and those who have one immigrant parent. Beyond being a control variable for the respondents' background, having one immigrant parent is also an indicator of long established contact with immigrants. So this variable is also of interest as a form of contact, and we would expect a mixed background to show a negative association with the attitudes variable.

Respondents in this study are still dependents of their parents. Thus, their socioeconomic background in the form of their parents' educational level and occupational status is used as a measure of socio-economic status. This approach is also in line with research done in the past concerning prejudice towards other out-groups (Bevelander and Hjerm, 2015). To further emphasize the importance of accounting for socioeconomic background, the transmission of attitudes from parent to child is an important explanatory factor. Gniewosz and Noack (2015) found such a transfer of attitudes to be strong up to about the age of 16 , which is the median age for respondents in the present data.

\section{Municipality-Wide Variables}

Research has shown that levels of unemployment are connected to negative attitudes and aggression towards immigrants. Coenders and Scheepers $(1998,2008)$ found that population cohorts who experienced high unemployment in their formative years exhibited more support for ethnic discrimination. Thus, adolescents who live in areas with a high level of unemployment may be in competition with immigrants over entrylevel jobs, which are thought to lead to an increased sense of economic threat, as has also been found in other previous research (Hjerm and Nagayoshi, 2011). In the statistical models, unemployment is the percentage of unemployed persons as measured by the Swedish Labor Office.

\section{Methods and Limitations}

We conducted two sets of regressions. We use models 1 and 2 to answer the first three questions of this study. The fourth and last question also relies on the results of models 3 and 4 . The ordinary least regression method is used to measure the association between contact and attitudes toward immigrants, while controlling for individual 
and structural background characteristics. The second pair of regressions is performed using fixed-effect models to account for unobserved heterogeneity, serving as a robustness check and evaluating the two models tested previously. Furthermore, if the effect size of the variables decreases significantly when fixed effects are used, this would also indicate that the relative importance of measures on these contextual levels is high as opposed to individual-level variables. Thus the last two models also contribute to distinguishing the relative importance of the three levels of measurement. We believe it is an advantage that we are able to include all variables of interest in the OLS models, whereas, if we used only fixed-effects models, we would not be able to see the effect sizes for all the contextual variables. With this combination of models, we balance the limitations of each approach and can see both the effect sizes of the contextual variables and the model fit of the models while, at the same time, controlling for the impact that the multilevel structure of the data has on the results. Beyond the inherent limitations of OLS and fixed-effects methods there are, of course, other limitations to the current methodological approach, with some stemming from the data themselves. Firstly, we can infer no causal relationships due to the lack of longitudinal data and analysis. Secondly, we cannot distinguish between contacts with immigrants from different regions of the world, which would have added a further interesting dimension to the analysis. Another limitation with using cross-sectional data for contact studies is the aforementioned self-selection bias that cannot be controlled for.

\section{Alternative Models}

As a further robustness check, we have also conducted the same analysis with a number of alternative non-reported models. The first included immigrants in the analysis so that the full sample can be analyzed; the second excludes individuals who have responded "I don't know" when asked if they have immigrant friends. The last controls for respondents' immigrant background with a 7-value measure of which region of the world they come from. This analysis confirmed that the model we rely on here is the one with the best fit and that these changes to the analysis did not significantly alter the results for our variables of interest.

\section{Results}

\section{Descriptive Results}

Table 2 shows the results for all categorical variables in our analysis. Girls are shown to have less-negative attitudes than boys; students in university preparatory programs have less-negative attitudes than those who attend vocational tracks or are still at secondary school. Respondents with one parent with higher education have lower negative attitudes, while those respondents with unemployed parents have a higher level of negative attitudes. Respondents with an immigrant parent and immigrant friends both each have lower negative attitudes toward immigrants.

Using bivariate correlations for our key variables and attitudes toward immigrants shows that negative attitudes are negatively related to having immigrant friends and that, if an individual has relatively more immigrants in their school class or in the 
municipality in which he or she lives, attitudes are usually less negative (Table 3). These results would indicate that both high-quality and superficial contact are associated with fewer negative attitudes toward immigrants. The results of our multivariate analysis are presented in the following section of the paper.

\section{Multivariate Results}

The results of models 1-4 are shown in Table 4. Model 1 includes only individual characteristics as control variables, as well as our key variables: number of friends and negative attitudes towards immigration. The model shows that these variables are indeed important for explaining negative attitudes and largely confirm what has been observed in earlier work. Gender has a statistically significant impact on negative attitudes, with boys having more-negative attitudes than girls. As noted before, this is a recurring finding in past research — while it is not clear why this gender difference is so consistent, it has theoretically been attributed to males' higher authoritarian personality (Adorno et al., 1950; Quillian, 1995). Living in a big city is associated with significantly lower negative attitudes as opposed to living in other parts of the country. This is possibly a peer effect, as negative attitudes are generally lower in the big urban areas; it could also be due to the different population pattern and demographic composition of the big cities compared to less urban areas. The socio-economic background variables show us that having at least one parent with higher education predicts attitudes that are moderately more positive, whereas, if one parent is

Table 2 Negative attitudes for all categorical variables, mean value and standard deviation

\begin{tabular}{|c|c|c|c|}
\hline & & Mean & Std Dev. \\
\hline \multirow[t]{2}{*}{ Gender } & Boys & .321 & .248 \\
\hline & Girls & .227 & .204 \\
\hline \multirow[t]{2}{*}{ Lives in a big city } & Yes & .209 & .216 \\
\hline & No & .294 & .234 \\
\hline \multirow[t]{2}{*}{ At least one parent with higher education } & Yes & .244 & .224 \\
\hline & No & .332 & .237 \\
\hline \multirow[t]{2}{*}{ At least one employed parent } & Yes & .275 & .233 \\
\hline & No & .314 & .243 \\
\hline \multirow[t]{2}{*}{ Family migration background } & One immigrant parent & .233 & .217 \\
\hline & Two Swedish parents & .282 & .235 \\
\hline \multirow[t]{3}{*}{ School track } & University preparatory & .203 & .194 \\
\hline & Vocational track & .374 & .240 \\
\hline & Secondary school & .278 & .226 \\
\hline \multirow[t]{5}{*}{ Number of immigrant friends } & No immigrant friends & .379 & .224 \\
\hline & One immigrant friend & .350 & .250 \\
\hline & A couple of immigrant friends & .278 & .222 \\
\hline & Many immigrant friends & .213 & .207 \\
\hline & I don't know & .279 & .230 \\
\hline$N$ for all variables & & & 5220 \\
\hline
\end{tabular}


Table 3 Bivariate correlations, negative attitudes, and contact variables

Contact variable

No immigrant friends

One immigrant friend

A couple of immigrant friends

Many immigrant friends

I don't know

Proportion of immigrants in school class

Proportion of immigrants in municipality
Negative attitudes

$0.159 * * *$

$0.100 * * *$

0.009

$-0.183^{* * * *}$

0.005

$-0.090 * * *$

$-0.134 * * *$

$* p<0.05 ; * * p<0.01 ; * * * p<0.001$

unemployed, they are insignificant. Living in a big city is also associated with lessnegative attitudes towards immigrants compared to those living in a municipality of any other size.

The association of attitudes with type and level of educational program emerges: students who are enrolled in vocational education have more-negative attitudes than those enrolled in university preparatory education; students enrolled in the last year of secondary school are younger and, in the coming years, will be engaged in either

Table 4 Multiple regression, effect of contact, and control variables on negative attitudes towards immigrants

\begin{tabular}{|c|c|c|c|c|}
\hline & $\begin{array}{l}\text { Model } 1 \\
\text { individual }\end{array}$ & $\begin{array}{l}\text { Model } 2 \\
\text { contextual }\end{array}$ & $\begin{array}{l}\text { Mod e } 13 \\
\text { school fixed }\end{array}$ & $\begin{array}{l}\text { M o d e } 14 \\
\text { municipality fixed }\end{array}$ \\
\hline Constant & $0.458 * * *$ & $0.369^{* * *}$ & $0.442 * * *$ & $0.411 * * *$ \\
\hline Gender, ref. Boy & $-0.0828 * * *$ & $-0.0806^{* * *}$ & $-0.0642 * * *$ & $-0.0756^{* * *}$ \\
\hline Lives in a big city, ref. No & $-0.0524 * * *$ & $-0.0698 * * *$ & & \\
\hline One+ parent high education, ref. No & $-0.0527 * * *$ & $-0.0477 * * *$ & $-0.0359 * * *$ & $-0.0429 * * *$ \\
\hline One+ parents with employment, ref. No & -0.0039 & 0.0279 & 0.0142 & 0.0067 \\
\hline University prep program & - & - & - & - \\
\hline Vocational training & $0.1550 * * *$ & $0.1560 * * *$ & & $0.1580 * * *$ \\
\hline Secondary school & $0.0661 * * *$ & $0.0624 * * *$ & & $0.0535 * * *$ \\
\hline $\begin{array}{l}\text { Born in Sweden with } 2 \text { Swedish parents, } \\
\text { ref. } 1 \text { immigrant parent }\end{array}$ & $0.0281^{* *}$ & $0.0275^{* *}$ & $0.0272 * *$ & $0.0271 * *$ \\
\hline No immigrant friends & - & - & - & - \\
\hline One immigrant friend & -0.0142 & -0.0155 & -0.0102 & -0.0128 \\
\hline A couple of immigrant friends & $-0.0879 * * *$ & $-0.0899 * * *$ & $-0.0828 * * *$ & $-0.0866 * * *$ \\
\hline Many immigrant friends & $-0.1470 * * *$ & $-0.1550 * * *$ & $-0.1410 * * *$ & $-0.1470 * * *$ \\
\hline I don’t know & $-0.0828 * * *$ & $-0.0810 * * *$ & $-0.0778 * * *$ & $-0.0784 * * *$ \\
\hline Proportion immigrants in school class & & $0.0514 *$ & & $0.0669 * *$ \\
\hline Proportion immigrants in municipality & & -0.0068 & & \\
\hline Unemployment in municipality & & $0.0107 * * *$ & & \\
\hline$N$ & 5220 & 5220 & 5217 & 5220 \\
\hline$r^{2}$ & 0.199 & 0.210 & & \\
\hline
\end{tabular}


vocational or university preparatory education. The results show that these students have only slightly more-negative attitudes than university preparatory students. The results also suggest the likelihood of self-selection into university-bound and vocational tracks. Parents' level of education predicts both their children's level of education and, to some degree, their attitudes. In addition, socialization in school might also contribute to explaining the school track effect. This is a combination of factors that has been found to have explanatory value in past research on the topic of education (Gniewosz and Noack, 2008).

As we could see in Table 2, adolescents with two parents born in Sweden have on average higher negative attitudes than their counterparts with one immigrant parent. In model 1, we further see that having two Swedish born parents is still associated with slightly higher negative attitudes, when all other variables are controlled for. It is interesting that this variable does not have a stronger association with negative attitudes considering that adolescents with one immigrant parent for the most part will have grown up having contact with at least one immigrant, and furthermore might have a mixed Swedish-Immigrant identity. Mixed identities importance for development of attitudes is not a well-researched issue, but one that could be interesting for future research.

The results for the key variable in our analysis - the number of immigrant friends among adolescent respondents, our friendship indicator - show clearly that having immigrant friends is associated with lower negative attitudes toward immigrants compared to those who have no immigrant friends. The "immigrant friend" variable indicates that more meaningful contact with immigrants is associated with a significant reduction in negative attitudes. Having many immigrant friends compared to having none is associated with a substantial decrease in the level of negative attitudes: the effect of this single variable is the strongest in the analysis. Having just a few friends with an immigrant background predicts a more-moderate decrease. It is, however, worth noting that having only one immigrant friend is not associated with any change in negative attitudes. This further indicates that there may be a threshold that needs to be crossed before contact reduces negative attitudes. The results show a pattern that is in line with the theoretical predictions made by Pettigrew and Tropp (2008) as well as Hodson (2011).

In model 2, we include structural variables approximating more-superficial contact with immigrants - the proportion of immigrants in a school class and municipality in order to see if this alters the results of model 1. The results show that the "contact in school" variable is of statistical significance and indicates that more immigrants in the class can be associated with more-negative attitudes. This result is contrary to what we had expected. The initial investigation of correlations between attitudes and the number of immigrants in the classroom showed a significant negative correlation, indicating that more potential contact in classrooms with one's immigrant peers is associated with more-positive attitudes. However, as was discussed previously, contact in the school setting has been observed to increase negative attitudes in previous research (see Gieling et al., 2014; Stark et al., 2015). The effect of "contact in the neighborhood," measured by the proportion of immigrants in the municipality, is not significant. Our understanding is that this variable is either not adequately measuring superficial contact or that this superficial contact and contact opportunities do not add anything more to the associations after high-quality contact has been accounted for. In past research, 
Rydgren and Ruth (2013) found that, in order to accurately model the effect of the proportion of minority-group members in an area on political behavior, more finegrained geographical analysis is required than is likely to be captured by a binary measurement of municipality size. It may be that this is the case for attitudes as well, suggesting that further research should strive to measure the size and ethnic composition of place with greater precision.

Adolescents who live in a municipality with a higher rate of unemployment have attitudes toward immigrants that are more negative: a $1 \%$ increase in unemployment corresponds to an increase in negative attitudes of just over $1 \%$. This result could indicate that adolescents who live in areas with a high level of unemployment might feel that their prospects of finding work are challenged by immigrants because both groups would be likely to compete for entry-level jobs. This finding is in line with Hjerm and Nagayoshi (2011), who found that economic threat matters for those among the majority who are in actual competition with out-groups.

Moreover, the measured coefficients for high-quality contact are very similar in model 2 compared to model 1, indicating that these results are robust. Similarity in model results also holds for the other coefficients measuring the individual characteristics of the sample; all in all, this reveals that close individual contact with immigrants is associated with lower negative attitudes towards immigrants.

Finally, in models 3 and 4, we carry out robustness checks of our results with the use of two regressions with fixed effect for school class-level variables (model 3) and municipalitylevel variables (model 4). In these models, we hold fixed variables measured at municipality and school class level. Again, we find very similar results for the friendship and other contact variables. However, the significance level of the school contact variable increases. For the control variables, we see only minor changes in effect sizes. Note that the model $N$ for model 3 is lower, as all higher-level groups must contain more than one individual, so three respondents had to be dropped for technical reasons.

\section{Discussion}

This article has addressed four initial questions:

- Does intergroup contact correlate with Swedish adolescents' attitudes towards immigrants, after controlling for other well-known factors?

- Is the size or direction of the correlation between contact and negative attitudes dependent on the type and amount of contact?

- Do superficial forms of contact in the school and local municipality contribute to explaining negative attitudes over and above what is explained by friendship and the high-quality contact that it represents?

- Finally, what is the relative importance of individual-level contact, as opposed to contact gauged by aggregate measures in the school class and local municipality?

To answer each of these questions, a large and representative survey of Swedish adolescents matched with registry data and official statistics was analyzed.

As is indicated by the contact variables in the analysis, close contact with one immigrant friend yields an insignificant result and neither increases nor decreases 
attitudes toward immigrants. However, having a larger number of immigrant friends is found to inversely correlate with negative attitudes, even after controlling for a number of background and contextual variables. This finding is in line with much previous research on contact effects (eg. Brown and Hewstone, 2005; Gieling et al., 2014; Pettigrew and Tropp, 2011; Pettigrew et al., 2008). However, the significance of the contact was not found to be as strong as in previous research. For example, the association found for the strongest contact variable ("having many immigrant friends") still falls short of the mean effect of contact found by Pettigrew and Tropp (2011) across 515 studies. In total, just over $5 \%$ of the variance in negative attitudes could be explained by contact variables. However, although this association is smaller than in previous research, it is clear that contact also affects negative attitudes in the setting under study. Even though contact in the school class correlated positively with negative attitudes, this does not counteract the association between having immigrant friends and negative attitudes. The reasons for the somewhat low observed association between contact and attitudes and the non-effect of having a sole immigrant friend may lie in the overall relatively positive attitudes towards immigrants that are found in this and earlier studies in Sweden (Bohman and Hjerm, 2016). Among individuals who already have relatively positive attitudes, something like a threshold effect has been observed, where further positive attitude interventions have little or no effect (Hodson, 2011). Pettigrew (1998) also argues that, after an initial contact effect, more reductions in prejudice require repeated and higher-quality contact. It should also be mentioned that all municipalities in Sweden have significant numbers of immigrants - the lowest observed proportion in our sample was $6.2 \%$. If a reduction in anxiety from initial contact is indeed the first and strongest mediator of contact effects on attitudes, as suggested by Pettigrew and Tropp (2008), it may be the case that youth in Sweden today have crossed this initial threshold and may offer a partial explanation for the observations made in the present study. These would be interesting questions for future research to investigate further.

In answer to the second question, we observed, firstly, that the type of contact clearly matters and that friendship is inversely associated with negative attitudes. We also observes that it is not enough to have just any amount of high-quality contact respondents need to have more than one friend for the association to be significant. Furthermore, corroborating findings that indicate a certain amount of contact needs to be surpassed for further improvements in attitudes to happen once an initial reduction has been achieved. The municipality-level contact variable has no explanatory power after high-quality contact is accounted for, while the school setting had a positive association between contact and negative attitudes. Based on this, it seems that superficial contact does not matter for negative attitudes beyond whatever increased amount of friendship it may predict - at least not for this population, where negative attitudes are relatively low. As for the school setting, this could be interpreted as support for findings that indicate diverging paths of contact, although this needs further information about the nature of contact before conclusions can be drawn. These results also answer the third question - whether superficial forms of contact in the school and local municipality contribute to explaining negative attitudes beyond what is determined by friendship and the high-quality contact that it represents. The results emerge as going counter to Pettigrew and Tropp's (2011) results, which show that superficial contacts could also correlate inversely with levels of negative attitudes, as well as 
earlier results by Hamberger and Hewstone (1997) — who focused on contact at work and in the neighborhood and contact as friendship and concluded that contact as friends was the only contact variable with explanatory power. While friendship was found to be the only variable that predicted lower levels of negative attitudes, the school setting clearly shows an opposite, albeit weaker, association. This also, interestingly, shows us that contact can be a driver of both increased and reduced negative attitudes. The type of contact clearly matters and should be a target for more focus in future research. The last question we asked concerned the relative importance of the individual level, as opposed to the school class and local municipality level. The results seem to indicate that the individual level is very important. The number of variables on the individual level is larger, so model explanatory power becomes misleading. However, when we use fixed effects, the effect strength of the individual-level variables also did not decrease much - indicating the robustness of the results and also that the school and municipality levels only account for a relatively small amount of the explained variance.

\section{Conclusion}

Given the very similar outcome for high-quality contact between the two sets of models, with and without fixed-effect superficial measurements, our understanding is that we should be careful when using contextual measures of superficial contact at the group level. Our results indicate that this type of proxy hides important underlying processes. Overall, the analysis indicates that, given the measured low level of negative attitudes toward immigrants among young Swedes, meaningful contact and interaction are necessary to reduce negative attitudes. Interestingly, we find that contact in the school setting increases negative attitudes - something that has also been found to be the case in past research but which deserves more attention in future research. This could possibly be done with more detailed measures of the type and amount of contact in this setting. More information about the school and school class could also help us to understand why this setting becomes a source of increased negative attitudes. This last point could potentially also be of high applicable value to teaching professionals and to education policy if it were to be explored further. Within the bounds of our paper, the significance of the increased negative attitudes from contact is that it shows clearly that the setting in which contact takes place is important. Unlike Pettigrew and Tropp's (2011) findings that superficial contact can be sufficient to reduce negative attitudes, we find that high-quality contact is absolutely necessary and that superficial contact might have the opposite effect in certain circumstances. This also increases our skepticism about using the presence of immigrants as a proxy for contact, without complementing it with other measures of contact, as has been done in some earlier contact studies.

We find that friendship is very important vis-à-vis other types of contact but, as long as we rely on the presence of immigrants as a proxy for superficial contact, we cannot with absolute certainty say whether superficial contact is insufficient to reduce negative attitudes. There remains the risk that it is the proxy variable that is not actually a good measure of contact. While we can say that the presence of immigrants in the local municipality is not sufficient to reduce negative attitudes, it may be that a focus on smaller or more specific geographical areas would give different results. So future 
studies would probably be well served if they tried to identify areas that are known to be socially relevant to the respondent or just more local than a municipality — like a school district or similar small geographical units. Furthermore, while the focus in this article has been on an overarching group of immigrants, an interesting addition to this would be to additionally measure interaction with specific ethnic or religious outgroups. Even though immigrants are a salient social category for adolescents, it would be interesting to know if attitudes towards this group are affected equally by contact with immigrants of all backgrounds. Lastly, it is also clear that it would be by far more preferable to have longitudinal data in future contact studies in order to counter the problems of self-selection and to be able to observe change and persistence in attitudes over time.

\section{Appendix}

Table 5 Descriptive statistics for all variables, mean, min, and max for quantitative variables, observations, and percentage for categorical variables

\begin{tabular}{|c|c|c|c|c|}
\hline & & & Freq. & Percent \\
\hline \multirow[t]{2}{*}{ Gender } & Boy & & 2677 & 51.28 \\
\hline & Girl & & 2543 & 48.72 \\
\hline \multirow[t]{2}{*}{ Lives in a big city } & Big city & & 1121 & 21.48 \\
\hline & Other & & 4099 & 78.52 \\
\hline \multirow[t]{2}{*}{ Family migration background } & Born in Sweden with mixed parents & & 690 & 13.22 \\
\hline & Born in Sweden with two Swedish parents & & 4530 & 86.78 \\
\hline \multirow[t]{2}{*}{ One+ parent with higher education } & No & & 1844 & 35.33 \\
\hline & Yes & & 3376 & 64.67 \\
\hline \multirow[t]{2}{*}{ One+ parent with employment } & No & & 97 & 1.86 \\
\hline & Yes & & 5123 & 98.14 \\
\hline \multirow[t]{5}{*}{ Immigrant friends } & No & & 590 & 11.30 \\
\hline & One & & 463 & 8.87 \\
\hline & A couple & & 2086 & 39.96 \\
\hline & Many & & 1655 & 31.70 \\
\hline & I don't know & & 426 & 8.16 \\
\hline \multirow[t]{4}{*}{ School track } & Secondary school & & 1726 & 33.07 \\
\hline & Vocational training & & 1129 & 21.63 \\
\hline & Uni. Prep. & & 2365 & 45.31 \\
\hline & & Mean & Min & Max \\
\hline Negative attitudes & & .276 & 0 & 1 \\
\hline Immigrants in the municipality & & $21.5 \%$ & $6.22 \%$ & $48.1 \%$ \\
\hline Immigrants in school class & & $16.8 \%$ & $0 \%$ & $96.3 \%$ \\
\hline Total $N$ for all variables & & & & 5220 \\
\hline
\end{tabular}


Funding Open access funding provided by Malmö University.

Open Access This article is licensed under a Creative Commons Attribution 4.0 International License, which permits use, sharing, adaptation, distribution and reproduction in any medium or format, as long as you give appropriate credit to the original author(s) and the source, provide a link to the Creative Commons licence, and indicate if changes were made. The images or other third party material in this article are included in the article's Creative Commons licence, unless indicated otherwise in a credit line to the material. If material is not included in the article's Creative Commons licence and your intended use is not permitted by statutory regulation or exceeds the permitted use, you will need to obtain permission directly from the copyright holder. To view a copy of this licence, visit http://creativecommons.org/licenses/by/4.0/.

\section{References}

Adorno, T., Frenkel-Brunswik, E., Levinson, D. J., \& Sanford, R. N. (1950). The authoritarian personality. Harper \& Row.

Agirdag, O., Demanet, J., Van Houtte, M., \& Van Avermaet, P. (2011). Ethnic school composition and peer victimization: A focus on the interethnic school climate. International Journal of Intercultural Relations, 35(4), 465-473. https://doi.org/10.1016/j.ijintrel.2010.09.009.

Allport, G. W. (1954). The nature of prejudice. Addison Wesley.

Bekhuis, H., Ruiter, S., \& Coenders, M. (2013). Xenophobia among youngsters: The effect of inter-ethnic contact. European Sociological Review, 29(2), 229-242. https://doi.org/10.1093/esr/jcr057.

Bevelander, P., \& Hjerm, M. (2015). The religious affiliation and anti-Semitism of secondary school-age Swedish youths: An analysis of survey data from 2003 and 2009. Ethnic and Racial Studies, 38(15), 2705-2721. https://doi.org/10.1080/01419870.2015.1042893.

Bevelander, P., \& Otterbeck, J. (2016). Swedish adolecents' attitudes towards immigrants. In J. Jamin (Ed.), L'extrême droite en Europe (pp. 282-299). Bruylant.

Binder, J., Zagefka, H., Brown, R., Funke, F., Kessler, T., Mummendey, A., Maquil, A., Demoulin, S., \& Leyens, J.-P. (2009). Does contact reduce prejudice or does prejudice reduce contact? A longitudinal test of the contact hypothesis among majority and minority groups in three European countries. Journal of Personality and Social Psychology, 96(4), 843-856. https://doi.org/10.1037/a0013470.

Bjørgo, T. (1997). Racist and right-wing violence in Scandinavia. Patterns and responses. Tano Aschehoug.

Blalock, H. (1967). Toward a theory of minority-group relations. Wiley.

Blumer, H. (1958). Race prejudice as a sense of group position. Pacific Sociological Review, 1(1), 3-7. https:// doi.org/10.2307/1388607.

Bohman, A., \& Hjerm, M. (2016). In the wake of radical right electoral success: A cross-country comparative study of anti-immigration attitudes over time. Journal of Ethnic and Migration Studies, 42(11), 17291747. https://doi.org/10.1080/1369183X.2015.1131607.

Borevi, K. (2018). Familj, medborgarskap, migration. Delegationen för Migrationsstudier.

Brown, R., \& Hewstone, M. (2005). An integrative theory of intergroup contact. Advances in Experimental Social Psychology, 37, 255-343. https://doi.org/10.1016/S0065-2601(05)37005-5.

Christ, O., \& Wagner, U. (2013). Methodological issues in the study of intergroup contact. In G. Hodson \& M. Hewstone (Eds.), Advances in intergroup contact (pp. 233-261). Psychology Press.

Coenders, M., \& Scheepers, P. (1998). Support for ethnic discrimination in the Netherlands 1979-1993: Effects of period, cohort, and individual characteristics. European Sociological Review, 14(4), 405-422. https://doi.org/10.1093/oxfordjournals.esr.a018247.

Coenders, M., \& Scheepers, P. (2003). The effect of education on nationalism and ethnic exclusionism: An international comparison. Political Psychology, 24(2), 313-343. https://doi.org/10.1111/0162-895X. 00330.

Coenders, M., \& Scheepers, P. (2008). Changes in resistance to the social integration of foreigners in Germany 1980-2000: Individual and contextual determinants. Journal of Ethnic and Migration Studies, 34(1), 126. https://doi.org/10.1080/13691830701708809.

Czaika, M., \& Di Lillo, A. (2018). The geography of anti-immigrant attitudes across Europe, 2002-2014. Journal of Ethnic and Migration Studies, 44(15), 2453-2479. https://doi.org/10.1080/1369183X.2018. 1427564. 
Davies, K., Tropp, L., Aron, A., Pettigrew, T., \& Wright, S. (2011). Cross-group friendships and intergroup attitudes: A meta-analytic review. Personality and Social Psychology Review, 15(4), 332-351. https://doi. org/10.1177/1088868311411103.

Demker, M., \& Van Der Meiden, S. (2016). Allt starkare polarisering och allt lägre flyktingmotstånd. In J. Ohlsson, H. Oscarsson, \& M. Solevid (Eds.), Ekvilibrium: SOM-undersökningen 2015 (pp. 192-214). SOM-insitutet.

Dixon, J. (2006). The ties that bind and those that don't: Toward reconciling group threat and contact theories of prejudice. Social Forces, 84(4), 2179-2204 https://www.jstor.org/stable/3844495.

Gieling, M., Thijs, J., \& Verkuyten, M. (2014). Dutch adolescents' tolerance of Muslim immigrants: The role of assimilation ideology, intergroup contact, and national identification. Journal of Applied Social Psychology, 44(3), 155-165. https://doi.org/10.1111/jasp.12220.

Gniewosz, B., \& Noack, P. (2008). Classroom climate indicators and attitudes towards foreigners. Journal of Adolescence, 31(5), 609-624. https://doi.org/10.1016/j.adolescence.2007.10.006.

Gniewosz, B., \& Noack, P. (2015). Parental influences on adolescents' negative attitudes toward immigrants. Journal of Youth and Adolescence, 44(9), 1787-1802. https://doi.org/10.1007/s10964-015-0291-3.

Gorodzeisky, A., \& Semyonov, M. (2009). Terms of exclusion: Public views towards admission and allocation of rights to immigrants in European countries. Ethnic and Racial Studies, 32(3), 401-423. https://doi.org/10.1080/01419870802245851.

Gorodzeisky, A., \& Semyonov, M. (2020). Perceptions and misperceptions: Actual size, perceived size and opposition to immigration in European societies. Journal of Ethnic and Migration Studies, 46(3), 612630. https://doi.org/10.1080/1369183X.2018.1550158.

Hainmueller, J., \& Hiscox, M. J. (2007). Educated preferences: Explaining attitudes toward immigration in Europe. International Organization, 61(02), 399-442. https://doi.org/10.1017/S0020818307070142.

Hamberger, J., \& Hewstone, M. (1997). Inter-ethnic contact as a predictor of blatant and subtle prejudice: Tests of a model in four West European nations. British Journal of Social Psychology, 36(2), 173-190. https://doi.org/10.1111/j.2044-8309.1997.tb01126.x.

Hellevik, O., \& Hellevik, T. (2017). Utviklingen i synet på innvandrere og innvandring i Norge. Tidsskrift for Samfunnsforskning, 58(3), 250-283. https://doi.org/10.18261/ISSN.1504-291X-2017-03-01.

Hello, E., Scheepers, P., Vermulst, A., \& Gerris, J. R. M. (2004). Association between educational attainment and ethnic distance in young adults: Socialization by schools or parents? Acta Sociologica, 47(3), 253275. https://doi.org/10.1177/0001699304046222.

Hellström, A., \& Edenborg, E. (2016). Politics of shame: Life stories of the Sweden democrats' voters in a counter public sphere. In J. Jérôme (Ed.), L'extrême droite en Europe (pp. 457-474). Bruylant.

Henry, P., \& Sears, D. (2002). The symbolic racism 2000 scale. Political Psychology, 23(2), 253-283. https:// doi.org/10.1111/0162-895X.00281.

Hjerm, M. (2001). Education, xenophobia and nationalism: A comparative analysis. Journal of Ethnic and Migration Studies, 27(1), 37-60. https://doi.org/10.1080/13691830124482.

Hjerm, M. (2009). Anti-immigrant attitudes and cross-municipal variation in the proportion of immigrants. Acta Sociologica, 52(1), 47-62. https://doi.org/10.1177/0001699308100633.

Hjerm, M., \& Nagayoshi, K. (2011). The composition of the minority population as a threat: Can real economic and cultural threats explain xenophobia? International Sociology, 26(6), 815-843. https://doi. org/10.1177/0268580910394004.

Hjerm, M., Eger, M. A., \& Danell, R. (2018). Peer attitudes and the development of prejudice in adolescence. Socius, 4, 1-11. https://doi.org/10.1177/2378023118763187.

Hodson, G. (2011). Do ideologically intolerant people benefit from intergroup contact? Current Directions in Psychological Science, 20(3), 154-159. https://doi.org/10.1177/0963721411409025.

Jugert, P., Eckstein, K., Beelmann, A., \& Noack, P. (2016). Parents' influence on the development of their children's ethnic intergroup attitudes: A longitudinal analysis from middle childhood to early adolescence. European Journal of Developmental Psychology, 13(2), 213-230. https://doi.org/10.1080/17405629. 2015.1084923.

Juvonen, J., Nishina, A., \& Graham, S. (2006). Ethnic diversity and perceptions of safety in urban middle schools. Psychological Science, 17(5), 393-400. https://doi.org/10.1111/j.1467-9280.2006.01718.x.

Laurence, J., \& Bentley, L. (2018). Countervailing contact: Community ethnic diversity, anti- immigrant attitudes and mediating pathways of positive and negative inter-ethnic contact in European societies. Social Science Research, 69, 83-110. https://doi.org/10.1016/j.ssresearch.2017.09.007.

Liebkind, K., Nyström, S., Honkanummi, E., \& Lange, A. (2004). Group size, group status and dimensions of contact as predictors of intergroup attitudes. Group Processes \& Intergroup Relations, 7(2), 145-159. https://doi.org/10.1177/1368430204041398.

Lövander, B. (2010). Den mångtydiga intoleransen. Forum för levande historia. 
McLaren, L. (2003). Anti-immigrant prejudice in Europe: Contact, threat perception, and preferences for the exclusion of migrants. Social Forces, 81(3), 909-936 https://www.jstor.org/stable/3598180.

Miklikowska, M. (2017). Development of anti-immigrant attitudes in adolescence: The role of parents, peers, intergroup friendships, and empathy. British Journal of Psychology, 108(3), 626-648. https://doi.org/10. 1111/bjop.12236.

Miller, S., \& Sears, D. (1986). Stability and change in social tolerance: A test of the persistence hypothesis. American Journal of Political Science, 30(1), 214-236 http://www.jstor.org/stable/2111302.

Pettigrew, T. (1997). Generalized intergroup contact effects on prejudice. Personality and Social Psychology Bulletin, 23(2), 173-185. https://doi.org/10.1177/0146167297232006.

Pettigrew, T., \& Tropp, L. (2008). How does intergroup contact reduce prejudice? Meta-analytic tests of three mediators. European Journal of Social Psychology, 38(January), 922-934. https://doi.org/10.1002/ejsp. 504.

Pettigrew, T., \& Tropp, L. (2011). When groups meet: The dynamics of intergroup contact. Psychology Press.

Pettigrew, T., Christ, O., Wagner, U., Meertens, R. W., van Dick, R., \& Zick, A. (2008). Relative deprivation and intergroup prejudice. Journal of Social Issues, 64(2), 385-401. https://doi.org/10.1111/j.1540-4560. 2008.00567.x.

Ponce, A. (2017). Gender and anti-immigrant attitudes in Europe. Socius: Sociological Research for a Dynamic World, 3, 237802311772997. https://doi.org/10.1177/2378023117729970.

Quillian, L. (1995). Prejudice as a response to perceived group threat: Population composition and antiimmigrant and racial prejudice in Europe. American Sociological Review, 60(4), 586-611 https://www. jstor.org/stable/2096296.

Ring, J., \& Morgentau, S. (2003). Intolerans: antisemitiska, homofobiska, islamofobiska och invandringsfientliga tendenser bland unga. Brå.

Rydgren, J., \& Ruth, P. (2013). Contextual explanations of radical right-wing support in Sweden: Socioeconomic marginalization, group threat, and the halo effect. Ethnic and Racial Studies, 36(4), 711-728. https://doi.org/10.1080/01419870.2011.623786.

Schmid, K., Hewstone, M., Küpper, B., Zick, A., \& Tausch, N. (2014). Reducing aggressive intergroup action tendencies: Effects of intergroup contact via perceived intergroup threat. Aggressive Behavior, 40(3), 250-262. https://doi.org/10.1002/ab.21516.

Severin, J. (2014). Tid för tolerans. Forum för levande historia.

Statistics Sweden. (2014). Teknisk rapport: En beskrivning av gjenomförande och metoder. Statistics Sweden http://www.levandehistoria.se/sites/default/files/material_file/teknisk_rapport_och_enkat.pdf.

Stark, T. H., Mäs, M., \& Flache, A. (2015). Liking and disliking minority-group classmates: Explaining the mixed findings for the influence of ethnic classroom composition on interethnic attitudes. Social Science Research, 50, 164-176. https://doi.org/10.1016/j.ssresearch.2014.11.008.

Thijs, J., \& Verkuyten, M. (2014). School ethnic diversity and students' interethnic relations. British Journal of Educational Psychology, 84(1), 1-21. https://doi.org/10.1111/bjep.12032.

Van Laar, C., Levin, S., Sinclair, S., \& Sidanius, J. (2005). The effect of university roommate contact on ethnic attitudes and behavior. Journal of Experimental Social Psychology, 41(4), 329-345. https://doi.org/ 10.1016/j.jesp.2004.08.002.

Vermeij, L., van Duijn, M. A. J., \& Baerveldt, C. (2009). Ethnic segregation in context: Social discrimination among native Dutch pupils and their ethnic minority classmates. Social Networks, 31(4), 230-239. https:// doi.org/10.1016/j.socnet.2009.06.002.

Vervoort, M. H. M., Scholte, R. H. J., \& Scheepers, P. L. H. (2011). Ethnic composition of school classes, majority-minority friendships, and adolescents' intergroup attitudes in the Netherlands. Journal of Adolescence, 34(2), 257-267. https://doi.org/10.1016/j.adolescence.2010.05.005.

Vogt, W. P. (1997). Tolerance and education: Learning to live with diversity and difference. Sage.

Wagner, U., \& Zick, A. (1995). The relation of formal education to ethnic prejudice: Its reliability, validity and explanation. European Journal of Social Psychology, 25(1), 41-56. https://doi.org/10.1002/ejsp. 2420250105.

Wagner, U., Christ, O., Pettigrew, T., Stellmacher, J., \& Wolf, C. (2006). Prejudice and minority proportion: Contact instead of threat effects. Social Psychology Quarterly, 69(4), 380-390. https://doi.org/10.1177/ 019027250606900406.

Wagner, U., Tropp, L. R., Finchilescu, G., \& Tredoux, C. (2009). Improving intergroup relations: Building on the legacy of Thomas F. Pettigrew. Wiley-Blackwell.

Wahl, K. (2002). Development of xenophobia and aggression. International Journal of Comparative and Applied Criminal Justice, 26(2), 247-256. https://doi.org/10.1080/01924036.2002.9678690. 
Weber, H. (2015). National and regional proportion of immigrants and perceived threat of immigration: A three-level analysis in Western Europe. International Journal of Comparative Sociology, 56, 116-140. https://doi.org/10.1177/0020715215571950.

Publisher's Note Springer Nature remains neutral with regard to jurisdictional claims in published maps and institutional affiliations. 